\title{
LEGAL AND ORGANIZATIONAL ASPECTS OF ORGAN DONATION AFTER IRREVERSIBLE CARDIAC ARREST
}

\author{
Lukasz Szarpak $^{1,2} 2^{(0}$, Karol Bielski ${ }^{2,3}{ }^{\oplus}$, Jacek Smereka ${ }^{2,4}{ }^{\infty}$, Piotr Raczka ${ }^{5}$ \\ ${ }^{1}$ Bialystok Oncology Center, Bialystok, Poland \\ ${ }^{2}$ Polish Society of Disaster Medicine, Warsaw, Poland \\ ${ }^{3}$ The Voivodship Emergency Medical Service and Sanitary Transport, Warsaw, Poland \\ ${ }^{4}$ Department of Emergency Medical Service, Wroclaw Medical University, Wroclaw, Poland
}

\begin{abstract}
Sudden cardiac arrest is a challenge for medical personnel. Donation after circulatory death (DCD) has opened new perspectives and could be a valuable option to expand the brain-dead donors. The purpose of this review is to provide an overview of current legal and organizational aspects of organ donation after irreversible cardiac arrest. The article presents basic issues related to the epidemiology of sudden cardiac arrest, criteria for the diagnosis of irreversible cardiac arrest. It also discusses special situations related to cardiac arrest and determining irreversible cardiac arrest in practice. Much attention has been paid to donor organ transplantation after irreversible cardiac arrest in the context of scientific research. This article aimed to present the Polish statutory and administrative regulations concerning donation after circulatory death. Following the 2010 Minister of Health's Notice on Criteria and Methods of Determining Irreversible Cardiac arrest, it should be stated that it legally allows for all types of donation included in the Mastricht classification.
\end{abstract}

KEY WORDS: irreversible cardiac arrest, transplantation, organ conditioning, legal act, cardiopulmonary resuscitation

Disaster Emerg Med J 2020; 5(3): 164-170

In Poland, the organ donation after cardiac arrest became legally permitted with the introduction in 2009 of a provision in the Act on Donation, Storage and Transplantation of Cells, Tissues and Organs (hereinafter: 'Transplantation Act') [1]. Over the years, legislative provisions on transplantology have developed further [2, 3].

According to the main rule of transplantology, the 'dead donor rule', it is unacceptable to donate vital organs for life before the natural death of the donor [5]. Therefore, most of the organs taken for transplantation come from the deceased [6]. In the United States, as in other countries, most organs transplanted are procured after determination of death by neurological criteria (BDD, brain dead do- nors) or planned withdrawal of life-sustaining therapy and donation after circulatory determination of death (DCD).

In the context of the DCD which is the subject of this article, there are two types of donation - controlled (CDCD) and uncontrolled ( $U D C D)$ DCD. The first category may include unexpected casualties and sudden cardiac arrest (SCA), and cardiopulmonary resuscitation (CPR) has been ineffective. The controlled donation, on the other hand, refers to the removal of organs from patients who have suffered cardiac arrest as a result of the planned withdrawal of life-support therapy. In addition to the general classification above, several more detailed distinctions can be made. Another example of the division 


\begin{tabular}{|} 
Table 1. The Modified Maastricht Classification of Donation after Circulatory Death \\
\hline Type of cardiac arrest & Donor category & Place of event & Definition \\
\hline $\begin{array}{l}\text { Uncontrolled cardiac } \\
\text { arrest }\end{array}$ & Type I & $\begin{array}{c}\text { Unwitnessed cardiac arrest: } \\
\text { IA - out of hospital } \\
\text { IB - in hospital }\end{array}$ & $\begin{array}{c}\text { Sudden, unexpected cardiac arrest without } \\
\text { attempted resuscitation by the medical team }\end{array}$ \\
\cline { 2 - 4 } & Type II & $\begin{array}{c}\text { Witnessed cardiac arrest: } \\
\text { IA - out of hospital } \\
\text { IIB - in hospital }\end{array}$ & $\begin{array}{c}\text { Sudden, unexpected and irreversible cardiac } \\
\text { arrest, with ineffective resuscitation by the } \\
\text { medical team }\end{array}$ \\
\hline Controlled cardiac arrest & Type III & \begin{tabular}{c} 
Expecting a cardiac arrest \\
\cline { 2 - 4 }
\end{tabular} & Type IV & $\begin{array}{c}\text { Cardiac arrest in a donor with brain } \\
\text { death. Controlled or uncontrolled }\end{array}$ & $\begin{array}{c}\text { Sudden or expected cardiac arrest during } \\
\text { diagnosis or after brain death }\end{array}$ \\
\hline
\end{tabular}

of DCD is based on the classification of donors after cardiac arrest, established at the Maastricht conference in 1995, which adopted the term 'Donation after Circulatory Death'. This term was originally intended to cover the term Non-Heart-Beating Donor (NHBD) which was used previously in Europe. In turn, in Paris in 2013, there was the 6th International Conference on Organ Donation after Circulatory Death, which clarified the Maastricht classification and definitions in the field of deceased organ donation particularly to DCD [7]. The categorisation of donors was adopted in 2013 (Tab. 1).

\section{EPIDEMIOLOGY OF SUDDEN CARDIAC ARREST}

Out-of-hospital cardiac arrest (OHCA) is worldwide quite a common disease and in Europe, about 350.000 persons are affected [8]. The World Health Organization (WHO) indicated that death from cardiovascular and respiratory diseases accounts for more than 20 million deaths [9].

In the United States, over 100.000 patients annually survive to hospital care after resuscitation from in- or out-of-hospital cardiac arrest, of which approximately $65 \%$ do not survive to discharge. Elmer et al. [10] indicated that each year approximately 167.000 OHCA patients are treated by the emergency medical services in the USA. Of these, $41.750(25 \%)$ are successfully resuscitated and admitted to an Intensive Care Unit.

\section{CRITERIA FOR THE DIAGNOSIS OF IRREVERSIBLE CARDIAC ARREST}

The criteria for establishing irreversible cardiac arrest were included in the Minister of Health's notice of
9 August 2010 [11], published based on the Act of 1 July 2005 on Donation, Storage and Transplantation of Cells, Tissues and Organs [12]. The present Notice contains indications on how irreversible cardiac arrest, including for organ transplantation, should be found.

While Article 9a, paragraph 3 of the Act on Collection, Storage and Transplantation of Cells, Tissues and Organs, which constitutes the basis for issuing the notice in question, was repealed as of 27 April 2017 by the Act of 24 February 2017 on amending the Act on the Professions of a Physician and a Dentist and the Act on the Collection, Storage and Transplantation of Cells, Tissues and Organs (Journal of Laws, item 767), under which the legal basis for issuing the notice in this matter was added in Article 43a(3)(2) of the Act on the Professions of a Physician and a Dentist; however, to this day the notice in question is a valid act. According to Article 3 of the Act of 2017, until the manner and criteria for establishing irreversible cardiac arrest before the donation of organs based on the Act on Professions of a Physician and a Dentist are announced, the criteria and manner announced under Article 9a(3) of the Act on Collection, Storage and Transplantation of Cells, Tissues and Organs apply. To date, the Minister of Health has not issued a new notice on this matter.

According to the above notice, irreversible cardiac arrest can be diagnosed concerning different clinical situations. The first of them is when during advanced CPR procedures, carried out according to the current knowledge and thus guidelines for cardiopulmonary resuscitation, asystole or pulseless electrical activity was observed for at least the last 20 minutes. Due to physiological differences in paediatric patients, the time should be longer and at least 45 minutes in children under two 
years. According to the guidelines for cardiopulmonary resuscitation, the patient's vital functions should be assessed every two minutes, which in the case of medical personnel comes down to the assessment of electrocardiographic rhythm and pulse presence on large arteries, including the carotid or femoral artery. According to the law, during the above-mentioned period of at least 20 minutes in the case of older children and adults and over 45 minutes in the case of children under two years, no pulse should be felt during the palpation test. At this point, it should be mentioned that the legislator had in mind the occurrence of a spontaneous pulse, which cannot be confused with a pulse wave caused by chest compressions during CPR procedures; hence, the pulse is assessed in the absence of chest compressions.

The second situation refers to asystole or PEA in the absence of a spontaneous pulse in the carotid or femoral arteries persisting continuously for at least 5 minutes after the end of ineffective cardiopulmonary resuscitation performed following the current guidelines for cardiopulmonary resuscitation.

If during the periods referred to in the preceding paragraphs, ventricular fibrillation or ventricular tachycardia or the return of a palpable spontaneous pulse on the carotid or femoral arteries occurs, the period of cardiopulmonary resuscitation and the subsequent observation of asystole or PEA is counted again from the beginning. During the described situation the stem reflexes are also assessed. The following are assessed: pupil response to light, corneal reflexes, vestibulo-ocular reflexes, any motor response to a pain stimulus applied to cranial nerve innervation, as well as a motor response in the face to pain stimuli applied to the spinal nerve area. Respiratory function is also assessed. The above procedures have been described in detail in the Minister of Health's notice of 4 December 2019 [13]. Besides, where an absence of stem reflexes cannot be established, the irreversible cardiac arrest shall be established based on the conditions described in the first situation [11]. Thanks to the development of medical technologies over the last decades and the increasing availability of modern devices in both pre-hospital and in-hospital settings, there are techniques for determining the quality of resuscitation $[14,15]$ and the return of spontaneous circulation [16]. Current guidelines for cardiopulmonary resuscitation published by the European Resuscitation Council $[17,18]$ and the American Heart Association
$[19,20]$ recommend that capnography should be used during CPR as a method to assess the correctness of airway management and ventilation. However, capnography - provided that the patient is properly ventilated - thanks to its sensitivity allows for rapid detection of the return of spontaneous circulation which is reflected by a rapid rise in the capnographic curve to values close to physiological ones $[16,21]$.

The third situation of irreversible cardiac arrest refers to the situation when sudden cardiac arrest occurs and the attending physician determines that according to current medical knowledge cardiopulmonary resuscitation will not result in survival. Then the five-minute countdown mentioned in the previous paragraph can be started, or chest compressions and ventilation can be started for organizational preparation for vascular catheterization and organ perfusion, and after the end of chest compressions and ventilation, the five-minute countdown can be started. The second option is more desirable from a medical point of view, as it allows minimal maintenance of organ perfusion and the exchange of metabolites, which improves the condition of the organs intended for potential transplantation. Besides, it is in line with Article 34 of the Code of Medical Ethics which states that: 'The physician, on the discovery of brain death, should maintain the functioning of cells, tissues and organs if they are to be transplanted' [22].

\section{SPECIAL SITUATIONS}

As in all recommendations related to the medical procedure, we can also list special situations - this is also the case here. The Minister of Health's notice lists four special situations in which the process of establishing irreversible cardiac arrest is systematized.

The first special situation indicated in the Notice is when we have to deal with a patient in hypothermia. In this case, the central body temperature of the patient should be brought to $35^{\circ} \mathrm{C}$, while providing cardiopulmonary resuscitation, and only then does the period of ineffective cardiopulmonary resuscitation count from this point on [23]. Of the recommended temperature test sites, the most accurate measurements are obtained on the eardrum or in the oesophagus.

In the case of patients with cardiac arrest, the time required to establish an irreversible arrest may 
be extended for organisational arrangements for vascular catheterization and organ perfusion, and at its completion, the observation referred to in the third paragraph of the second chapter may begin.

Another situation described refers to cardiac arrest, which occurred when brain death was diagnosed: however, before the necessary instrumental and clinical examinations were performed. In such cases, cardiopulmonary resuscitation should be undertaken and, if circulation is restored, the brain death recognition procedure should be restarted. If cardiopulmonary resuscitation is ineffective, it should be performed as in the case of diagnosing irreversible cardiac arrest. On the other hand, if cardiac arrest occurred after an instrumental test confirming brain death is performed, the procedure provided in Part II of the Minister of Health Health's Notice of 4 December 2019 on the method and criteria for determining irreversible brain death should be initiated.

\section{DETERMINING IRREVERSIBLE CARDIAC ARREST IN PRACTICE}

To establish an irreversible cardiac arrest, the physician should use the above-described recommendations included in the Ministerial Notice [11]. According to this Notice, a physician establishing irreversible cardiac arrest for organ donation is obliged to consult two physicians selected from among specialists in the following fields of medicine: anaesthesiology and intensive care, emergency medicine, cardiology, paediatric cardiology or internal diseases. The opinion is based on the signature of the protocol of irreversible cardiac arrest. (Suppl. 1). In a situation where a physician establishing irreversible cardiac arrest has a specialization in the medical fields listed above, he or she can use only one opinion from another specialist in the above-mentioned fields of medicine. The above provisions apply to in-hospital settings; however, in the case of actions taken by ambulances, the only possible solution is the use of mechanical chest compression systems, which enable high-quality chest compressions to be performed during patient transport to the hospital. The next step is to connect the patient to ExtraCorporeal Membrane Oxygenation (ECMO). ECMO is an extracorporeal system containing a pump and an oxygenator that allows the lungs and/or heart to be replaced for some time by extracorporeal oxygenation of the blood and elimination of carbon dioxide. Such actions increase the chance that the organ will be suitable for transplantation and that it will function properly $[24,25]$.

\section{DONOR ORGAN TRANSPLANTATION AFTER IRREVERSIBLE CARDIAC ARREST IN THE CONTEXT OF SCIENTIFIC RESEARCH}

Approximately 120.000 organ transplants are performed each year; therefore, the WHO estimates that this number of transplants only resolves $10 \%$ of the annual worldwide transplant need [9]. As shown in the previous sections of the article on the epidemiology of cardiac arrest, according to WHO 20 million deaths caused by cardiovascular and respiratory diseases theoretically could be used for DCD.

Many organ types such as kidney, liver, pancreas, lung and, recently, heart donation are eligible for controlled DCD, although this varies by country [26]. In the uncontrolled DCD (UDCD), kidneys, livers and lungs have successfully been transplanted; an example of such actions can be the 'ECMO for Wielkopolska' programme introduced in Wielkopolska (Poland) under which the first UDCD transplants have already been performed [27, 28]. In the world, DCD is becoming increasingly important as an alternative to brain death donors. A good example is the United Kingdom, where DCD-transplanted organs accounted for $19 \%$ in 2007 and increased to $43 \%$ of all transplants in 2016 [29].

DCD can be used in the case of irreversible cardiac arrest and thus ineffective cardiopulmonary resuscitation, moreover, as already mentioned; it can be used after the cessation of futile therapy as a controlled version of DCD. In countries where it is legal, such as Belgium and in the Netherlands, DCD has been performed after euthanasia [30].

It is worth noting that Polish regulations, and in particular the regulation contained in the Act of 1 July 2005 on the Collection, Storage and Transplantation of Cells, Tissues and Organs, do not differentiate the prerequisites to be met for the collection of human cells, tissues and organs from corpses, based on the criterion of the cause of death. In particular, according to Article 4 of this Act, cells, tissue and organs may be collected from human corpses for, inter alia, therapeutic purposes after death has been established in the manner laid down in the Act on the professions of physician and dentist. However, the provisions of this Act provide for the declaration of death either in the case of permanent irreversible cessation of brain function 


\section{PROTOCOL FOR DIAGNOSIS OF IRREVERSIBLE CARDIAC ARREST}

1. Name of the person diagnosed with irreversible cardiac arrest

2. PESEL number.

3. Cause of irreversible cardiac arrest.

4. Time (hour and minute) to start CPR

5. Time (hour and minute) from which the period during which no ventricular fibrillation or spontaneous pulse wave was found during CPR was counted

6. Time (hour and minute) to start the 5 -minute observation period after CPR is completed

7. Time (hour and minute) of the end of the 5-minute observation period after the end of CPR......

8. The period of ineffective CPR was at least 20 minutes in adults or at least 45 minutes in children under 2 years of age*

9. No pupil response to light was found *

10. No corneal reflex was found *

11. No vestibulo-ocular reflexes were found *

12. No response to painful stimuli was found *

13. No respiratory function was found *

14. At least 5-minute observation period after the end of CPR has passed *

15. The central body temperature exceeded $35^{\circ} \mathrm{C}^{*}$

The physician giving the opinion stated irreversible cardiac arrest in the manner consistent with the announcement of the Minister of Health of 9 August 2010 on the criteria and manner of stating the irreversible cardiac arrest

on at the hour

(physician stamp and signature)

The physician giving the opinion stated irreversible cardiac arrest in the manner consistent with the announcement of the Minister of Health of 9 August 2010 on the criteria and manner of stating the irreversible cardiac arrest

on at the hour

(physician stamp and signature)

Death due to irreversible cardiac arrest was confirmed by a physician confirming the irreversible cardiac arrest

(physician stamp and signature) at the hour

* Indicate: yes, no or no investigation (with reason).

SUPPLEMENT 1. Protocol for diagnosis of irreversible cardiac arrest

(brain death) or irreversible cardiac arrest preceding the removal of organs. In both cases, the removal of cells, tissues and organs is possible under the conditions specified in Chapter 2 of the 2005 Act.

\section{SUMMARY}

This article aimed to present the Polish statutory and administrative regulations concerning donation after circulatory death. Following the 2010 Minister of Health's Notice on Criteria and Methods of Determining Irreversible Cardiac arrest, it should be stated that it legally allows for all types of donation included in the Mastricht classification [10].

\section{Financial support and sponsorship}

None. 


\section{Conflicts of interest}

There are no conflicts of interest.

\section{REFERENCES}

1. An Amending Act. BMJ. 1948; 1(4553): 694-695, doi: 10.1136/ bmj.1.4553.694.

2. An Amending Act. BMJ. 1948; 1(4553): 694-695, doi: 10.1136/ bmj.1.4553.694.

3. Sahay M. Transplantation of human organs and tissues act. Indian Journal of Transplantation. 2020; 14(2): 188, doi: 10.4103/ijot.ijot_59_20.

4. The announcement by the Speaker of the Sejm of the Republic of Poland of 14 June 2019 on the announcement of the consolidated text of the Act on the collection, storage and transplantation of cells, tissues and organs. Journal of Laws. ; 2019: item.

5. Miller FG, Truog RD, Brock DW. The dead donor rule: can it withstand critical scrutiny? J Med Philos. 2010; 35(3): 299-312, doi: 10.1093/ jmp/jhq019, indexed in Pubmed: 20439355.

6. Rodríguez-Arias D. The Dead Donor Rule as Policy Indoctrination. Hastings Cent Rep. 2018; 48 Suppl 4: S39-S42, doi: 10.1002/hast.952, indexed in Pubmed: 30584844.

7. Thuong M, Ruiz A, Evrard $P$, et al. New classification of donation after circulatory death donors definitions and terminology. Transpl Int. 2016; 29(7): 749-759, doi: 10.1111/tri.12776, indexed in Pubmed: 26991858.

8. Manara A, Domínguez-Gil B. Controlling the uncontrolled: Can we realise the potential of uncontrolled donation after circulatory death? Resuscitation. 2019; 137: 234-236, doi: 10.1016/j.resuscitation.2019.02.010, indexed in Pubmed: 30790689.

9. WHO - The top 10 causes of death - Fact sheet. Updated January 2017. http://www.who.int/mediacentre/factsheets/fs310/en/. [Accessed 1 July. ; 2020.

10. Elmer J, Torres C, Aufderheide TP, et al. Resuscitation Outcomes Consortium. Association of early withdrawal of life-sustaining therapy for perceived neurological prognosis with mortality after cardiac arrest. Resuscitation. 2016; 102: 127-135, doi: 10.1016/j.resuscitation.2016.01.016, indexed in Pubmed: 26836944.

11. Announcement. Zygon®. 2010; 45(3): 784-784, doi: 10.1111/j.14679744.2010.01132.x.

12. Act of 1 July 2005 on the collection, storage and transplantation of cells, tissues and organs. Journal of Laws 2005 No. ; 169: item.

13. Brain Death Criteria. Acute Stroke Care. 2019: 262-265, doi: 10.1017/9781108759823.022.

14. Smereka J, Szarpak L, Czekajlo M, et al. The TrueCPR device in the process of teaching cardiopulmonary resuscitation: A randomized simulation trial. Medicine (Baltimore). 2019; 98(27): e15995, doi: 10.1097/MD.0000000000015995, indexed in Pubmed: 31277091.

15. Truszewski Z, Szarpak L, Kurowski A, et al. Randomized trial of the chest compressions effectiveness comparing 3 feedback CPR devices and standard basic life support by nurses. Am J Emerg Med. 2016; 34(3): 381-385, doi: 10.1016/j.ajem.2015.11.003, indexed in Pubmed: 26612703.
16. Hawkes GA, Finn D, Kenosi M, et al. A Randomized Controlled Trial of End-Tidal Carbon Dioxide Detection of Preterm Infants in the Delivery Room. J Pediatr. 2017; 182: 74-78.e2, doi: 10.1016/j. jpeds.2016.11.006, indexed in Pubmed: 27939108.

17. Soar J, Nolan JP, Böttiger BW, et al. Adult advanced life support section Collaborators. European Resuscitation Council Guidelines for Resuscitation 2015: Section 3. Adult advanced life support. Resuscitation. 2015; 95: 100-147, doi: 10.1016/j.resuscitation.2015.07.016, indexed in Pubmed: 26477701.

18. Maconochie IK, Bingham R, Eich C, et al. Paediatric life support section Collaborators. European Resuscitation Council Guidelines for Resuscitation 2015: Section 6. Paediatric life support. Resuscitation. 2015; 95: 223-248, doi: 10.1016/j.resuscitation.2015.07.028, indexed in Pubmed: 26477414.

19. Link MS, Berkow LC, Kudenchuk PJ, et al. Part 7: Adult Advanced Cardiovascular Life Support: 2015 American Heart Association Guidelines Update for Cardiopulmonary Resuscitation and Emergency Cardiovascular Care. Circulation. 2015; 132(18 Suppl 2): S444-S464, doi: 10.1161/CIR.0000000000000261, indexed in Pubmed: 26472995.

20. de Caen AR, Berg MD, Chameides L, et al. Part 12: Pediatric Advanced Life Support: 2015 American Heart Association Guidelines Update for Cardiopulmonary Resuscitation and Emergency Cardiovascular Care (Reprint). Pediatrics. 2015; 136 Suppl 2(18 Suppl 2): S176-S195, doi: 10.1542/peds.2015-3373F, indexed in Pubmed: 26471384.

21. Nakatani $K$, Yukioka H, Fujimori M, et al. Utility of colorimetric end-tidal carbon dioxide detector for monitoring during prehospital cardiopulmonary resuscitation. The American Journal of Emergency Medicine. 1999; 17(2): 203-206, doi: 10.1016/50735-6757(99)90062-1.

22. The Code of Medical Ethics. Kennedy Institute of Ethics Journal. 1992; 2(4): 371-384, doi: 10.1353/ken.0.0058.

23. Lavonas EJ, Drennan IR, Gabrielli A, et al. Part 10: Special Circumstances of Resuscitation: 2015 American Heart Association Guidelines Update for Cardiopulmonary Resuscitation and Emergency Cardiovascular Care. Circulation. 2015; 132(18 Suppl 2): S501-S518, doi: 10.1161/CIR.0000000000000264, indexed in Pubmed: 26472998.

24. Rubio Muñoz JJ, Dominguez-Gil González B, Miñambres García E, et al. Role of normothermic perfusión with ECMO in donation after controlled cardiac death in Spain. Med Intensiva. 2020 [Epub ahead of print], doi: 10.1016/j.medin.2020.01.017, indexed in Pubmed: 32564985.

25. Kukreja J, Tsou S, Chen J, et al. Risk Factors and Outcomes of Extracorporeal Membrane Oxygenation as a Bridge to Lung Transplantation. Semin Thorac Cardiovasc Surg. 2020 [Epub ahead of print], doi: 10.1053/j.semtcvs.2020.05.008, indexed in Pubmed: 32445793.

26. Manyalich M, Nelson H, Delmonico FL. The need and opportunity for donation after circulatory death worldwide. Curr Opin Organ Transplant. 2018; 23(1): 136-141, doi: 10.1097/MOT.00000000000000486, indexed in Pubmed: 29206661.

27. Puślecki $M$, Ligowski $M$, Dąbrowski $M$, et al. „ECMO for Greater Poland": a unique regional program for extracorporeal life support. Pol Arch Intern Med. 2017; 127(7-8): 567-568, doi: 10.20452/ pamw.4082, indexed in Pubmed: 28817549. 
28. Puślecki M, Ligowski M, Stefaniak S, et al. „Extracorporeal Membrane Oxygenation for Greater Poland" Program: How to Save Lives and Develop Organ Donation? Transplant Proc. 2018; 50(7): 1957-1961, doi: 10.1016/j.transproceed.2018.02.159, indexed in Pubmed: 30177087.

29. Broderick AR, Manara A, Bramhall S, et al. A Donation After Circulatory Death Program Has the Potential to Increase the Number of Donors
After Brain Death. Crit Care Med. 2016; 44(2): 352-359, doi: 10.1097/ CCM.0000000000001384, indexed in Pubmed: 26491863.

30. van Dijk G, van Bruchem-Visser R, de Beaufort I. Organ donation after euthanasia, morally acceptable under strict procedural safeguards. Clin Transplant. 2018; 32(8): e13294, doi: 10.1111/ctr.13294, indexed in Pubmed: 29791757. 